\title{
Influence of dispersoids on the creep behavior of dispersion strengthened aluminum materials
}

\author{
F. Carreño and O.A. Ruano $\left.{ }^{*}\right)$
}

\begin{abstract}
The creep behavior of a rapidly solidified Al-6.5\% Fe- $0.6 \% \mathrm{~V}-1.3 \% \mathrm{Si}$ dispersion strengthened material containing 16 volume $\%$ of dispersoids has been studied by means of tensile tests at high temperatures from 483 to $821 \mathrm{~K}$. The imposed strain rates ranged from $2.5 \cdot 10^{-6}$ to $10^{-2} \mathrm{~s}^{-1}$. The microstructure was very fine, consisting of submicron grains and small hard round-shaped dispersoids of about $54 \mathrm{~nm}$. The creep behavior was characterized by high apparent stress exponents and high activation energies that are not accurately predicted by models from the literature. Therefore, a creep equation is developed to describe the creep behavior of the studied aluminum dispersion strengthened material and other materials with similar microstructures. The proposed equation is a generalization of conventional slip creep equations without the use of a threshold stress.
\end{abstract}

Keywords: Creep. Al alloys. Dispersion strengthened alloys.

\section{Influencia de los dispersoides en el comportamiento en fluencia de materiales de aluminio reforzados por dispersion}

\begin{abstract}
Resumen Se estudió el comportamiento en fluencia del material solidificado rápidamente Al-6,5\% Fe-0,6\% $1,3 \% \mathrm{Si}$, reforzado por dispersión que contenía una fracción de volumen de dispersoides de $16 \%$, mediante ensayos de tracción a altas temperaturas desde 483 a $821 \mathrm{~K}$. Las velocidades de " deformación impuestas variaron desde $2,5 \cdot 10^{-6}$ a $10^{-2} \mathrm{~s}^{-1}$. La microestructura, que era muy fina, estaba formada por granos submicrométricos y pequeños dispersoides redondeados y duros de unos $54 \mathrm{~nm}$. El comportamiento en fluencia se caracterizó por altos exponentes de la tensión aparente y altas energías de activación aparentes que no se predicen con exactitud por modelos de la literatura. Por ello, se ha desarrollado una ecuación de fluencia que describe el comportamiento del material de base aluminio reforzado por dispersión y de otros materiales de microestructura similar. La ecuación propuesta es una generalización de ecuaciones de fluencia convencionales por movimiento de dislocaciones y no emplea una tensión umbral.
\end{abstract}

Palabras clave: Fluencia. Aleaciones de aluminio. Aleaciones reforzadas por dispersión.

\section{INTRODUCTION}

Considerable research has been conducted on rapidly solidified and powder processed aluminum alloys due to the fine microstructures obtained that ensure outstanding mechanical properties at extended service temperatures beyond $473 \mathrm{~K}$ (1-7).

(•) Trabajo recibido el día 26 de diciembre de 1996.

(*) Dpto. de Metalurgia Física. Centro Nacional de Investigaciones Metalúrgicas (CENIM) C.S.I.C. Avda. Gregorio del Amo, 8. 28040-Madrid (España).
Al-Fe alloys with ternary additions of transition metals have promised lightweight structural materials due to their low diffusivity in the aluminum matrix and have been studied extensively $(8-18)$. The addition of silicon to these systems allowed the formation of a large volume fraction of very fine, rounded and thermally stable silicides (19-20). These alloys are specially creep resistant due to the much slower coarsening rate of the silicides.

These alloys and other dispersion strengthened materials present an "anomalous" creep behavior compared to pure metals and dispersion-free alloys, 
referring to the high apparent stress exponent and activation energy values when tested at high temperatures.

The stress exponent for creep of these materials is much higher than 5, extending over several decades in strain rate. On the other hand, the activation energy for creep is much higher than that for lattice self-diffusion (21-24). These two creep parameters, $n$ and $Q$, are determined from the general creep equation

$$
\dot{\varepsilon}=A_{\mathrm{PL}}\left(\frac{\sigma}{E}\right)^{\mathrm{n}} \exp \left(\frac{-Q}{R T}\right)
$$

where $\dot{\varepsilon}$ is the strain rate, $A_{\mathrm{PL}}$ is a material constant, $\sigma$ is the stress, $n$ is the stress exponent, $Q$ is the activation energy for creep, $E$ is Young's modulus, $R$ is the gas constant and $T$ is the temperature. The stress exponent and activation energy obtained experimentally from $\dot{\varepsilon} v s \sigma / E$ curves at different temperatures using eq. [1] are normally referred as apparent, $n_{\mathrm{ap}}$ and $Q_{\mathrm{ap}}$, respectively.

At constant structure creep tests, as expected in dispersion-strengthened alloys, the following equation can be used in the power law creep region (21 and 25):

$$
\dot{\varepsilon}=A_{\lambda}\left(\frac{\lambda}{b}\right)^{3}\left(\frac{\sigma}{E}\right)^{8}\left(\frac{D_{\mathrm{L}}}{b^{2}}\right)
$$

In this equation, $\lambda$ is the subgrain size and $b$ is Burgers vector. The constant $A_{\lambda}$ is*equal to $10^{9}$ and $D_{\mathrm{L}}=D_{0} \exp \left(-Q_{\mathrm{L}} / R T\right)$ is the lattice self-diffusion coefficient, where $D_{0}$ is the preexponential constant and $Q_{\mathrm{L}}$ is the activation energy for lattice selfdiffusion.

The activation energies for creep and the stress exponents of dispersion-strengthened materials are often found to be too high to be explained by this equation. A formal representation of the creep data for such materials can be obtained by introducing a threshold stress, $\sigma_{0}$, into eq. [1]. Below this stress, creep deformation is assumed to be negligible. This assumption leads to an arbitrarily high apparent stress exponent on $\log \dot{\varepsilon}-\log \sigma$ plots in the vicinity of $\sigma_{0}$. By curve fitting, consistent sets of values for $Q$ and $n$ (where $n$ can be 2, 3,5 or 8) can usually be found which enable eq. [1] to describe the creep data within a certain range of experimental conditions $(21-23,26-35)$. The inadequacies of this parametric approach are however quite evident: the parameter $\sigma_{0}$ is not a good material constant as it often varies with both temperature and applied stress.

There are a number of other approaches to explain the anomalous creep behavior, for example, to consider that the dispersoids deform also at high temperatures (36-37), load transfer between matrix and particles (38-39) or dislocation-dispersoid interaction (33-34, 40-45), but these approaches do not warrant a proper prediction of the creep behavior.

The purpose of this paper is to study the creep behavior of a rapidly solidified extruded $\mathrm{Al}-\mathrm{Fe}-\mathrm{V}-\mathrm{Si}$ dispersion strengthened material and to develop a phenomenological relation that permits a quantitative prediction for dispersion strengthened materials that do not show threshold stress-like behavior. The predictions of the new equation are compared with the creep data of both the extruded material studied in this work and a rolled material of similar composition that was previously investigated (46).

\section{MATERIAL AND EXPERIMENTAL PROCEDURE}

An extruded material of composition $\mathrm{Al}-6.5 \% \mathrm{Fe}-$ $0.6 \% \mathrm{~V}-1.3 \% \mathrm{Si}$ (in mass percent) was studied. The abbreviated denomination is "extruded AFV-16\%". The material denomination is given by the initials of the elements present except for silicon. The percent amount following those initials corresponds to the volume fraction of dispersoids in the material.

The material was obtained at Allied-Signal laboratories. It was rapidly solidified by "planar flow casting", producing ribbons of approximately $25 \mu \mathrm{m}$ in thickness and $50 \mathrm{~mm}$ in width at cooling rates of up to $10^{6} \mathrm{~K} / \mathrm{s}$ (47).

The ribbons were then comminuted to powder and were processed by a powder metallurgy route. The powders were first sieved to have particles smaller than about $200 \mu \mathrm{m}$ and then degassified and hot pressed at $623 \mathrm{~K}$ in vacuum. Billets of $279 \mathrm{~mm}$ in diameter were obtained. The ingots were preheated at $673 \mathrm{~K}$ and extruded at an extrusion ratio of $9.8: 1$ to obtain bars of $89 \mathrm{~mm}$ in diameter.

Cylindrical tensile samples of $4.8 \mathrm{~mm}$ in diameter and $19 \mathrm{~mm}$ gauge length were machined parallel to the extrusion direction.

Specimens were tested at temperatures ranging from 483 to $821 \mathrm{~K}$, and strain rates ranging from $2.5 \cdot 10^{-6}$ to $10^{-2} \mathrm{~s}^{-1}$.

\section{RESULTS}

The microstructure of the extruded AFV-16\% material was found to consist of very fine grains and small and rounded dispersoids. The grain size is about $0.7 \mu \mathrm{m}$ and the dispersoids, of approximately $54 \mathrm{~nm}$, are homogeneously distributed in the matrix. The vast majority of dispersoids found are of the $\mathrm{Al}_{12}(\mathrm{Fe}, \mathrm{V})_{3} \mathrm{Si}$ phase, being the rest of the $\mathrm{Al}_{13}(\mathrm{Fe}, \mathrm{V})_{4}$ phase. The microstructure after testing at 
temperatures up to $673 \mathrm{~K}$ showed that the grain and dispersoid sizes remain very fine. The microstructure of the material remains homogeneous after tensile testing.

In order to characterize the creep behavior of the dispersion strengthened material, strain rate-flow stress data at different temperatures were obtained by means of strain rate changes. The tests started at the highest strain rate of $10^{-2} \mathrm{~s}^{-1}$ until constant flow stress is reached. Then, decreasing steps of an order of magnitude in strain rate were imposed. The material showed a typical constant substructure deformation behavior since, after a change in strain rate, a new steady state was quickly developed after a small deformation (25).

Figure 1 shows a plot of logarithm of the true strain rate, $\dot{\varepsilon}$, as a function of logarithm of the true flow stress, $\sigma$, for the extruded AFV-16\% material. The flow stresses range from 41 to $258 \mathrm{MPa}$ for applied strain rates ranging from $2.5 \cdot 10^{-6}$ to $10^{-2} \mathrm{~s}^{-1}$ and temperatures ranging from 483 to $821 \mathrm{~K}$.

The apparent stress exponent, $n_{\mathrm{ap}}$, and the apparent activation energy, $Q_{\text {ap }}$, are directly obtained from figure 1 ,

$$
n_{\mathrm{ap}}=\left.\frac{\partial \ln \dot{\varepsilon}}{\partial \ln \sigma}\right|_{\mathrm{T}} \quad Q_{\mathrm{ap}}=n_{\mathrm{ap}} \cdot R\left[\frac{\Delta \ln \left(\frac{\sigma}{E}\right)}{\Delta\left(\frac{1}{T}\right)}\right]_{\dot{\varepsilon}}
$$

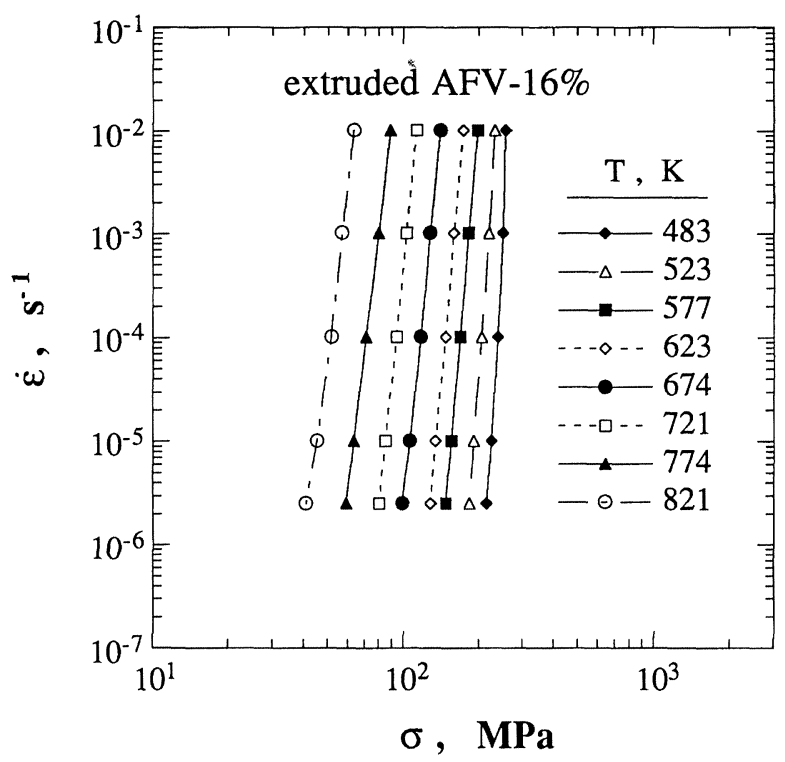

Fig. 1.-Strain rate $v s$ flow stress for the extruded AFV-16\% material at various temperatures.

Fig. 1.-Velocidad de deformación en función de la tensión a varias temperaturas del material AFV$16 \%$ extruido. where $R$ is the gas constant. To avoid extrapolations, the activation energy for creep was determined at a constant strain rate of $10^{-4} \mathrm{~s}^{-1}$. Values of the Young's modulus for pure aluminum at different temperatures were used (48).

Figure 2 shows the apparent activation energy and the apparent stress exponent as a function of temperature for the extruded AFV-16\% material in the temperature range 483 to $821 \mathrm{~K}$. The large activation energy values found at high temperatures (up to $550 \mathrm{~kJ} / \mathrm{mol}$ ) do not correspond to activation energies of any kind of diffusivity that may control deformation in these systems. Thus, these very high values of activation energies should be rationalized to explain the creep behavior. The stress exponent values, on the other hand, decrease with increasing temperature from 44 at $483 \mathrm{~K}$ to 19 at $821 \mathrm{~K}$. These high values are in contrast to non-reinforced materials that usually show a stress exponent of about 5 at elevated temperatures which remain unchanged in a wide range of temperatures. These stress exponents are even higher than that of 8 , corresponding to the creep model under constant substructure conditions (25).

It is of interest to note that the anomalously high values of $n_{\mathrm{ap}}$ and $Q_{\mathrm{ap}}$ are also found in dispersion and particulate reinforced materials (21-24). However, they are not encountered in pure metals and solid solutions (49).

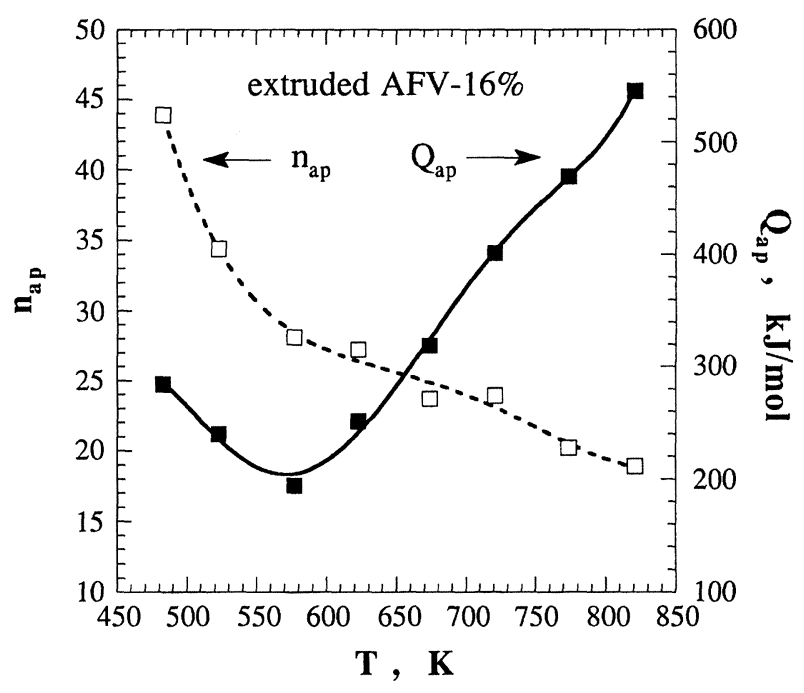

Fig. 2.- The apparent activation energy and the apparent stress exponent $v s$ testing temperature for the extruded AFV- $16 \%$ material.

Fig. 2.-La energía de activación aparente y el exponente de la tensión aparente en función de la temperatura de ensayo del material AFV-16\% extruido. 


\section{DISCUSSION}

Several attempts have been made in the literature to rationalize the high values of $n_{\text {ap }}$ and $Q_{\text {ap }}$ often observed in dispersion strengthened materials. An usual approach is to fit the creep data considering some creep mechanism and incorporating a threshold stress. The threshold stress is then related to that particular mechanism chosen. For example, the stress necessary to start the motion of dislocations if slip creep is considered. The most common slip creep mechanisms incorporating a threshold stress used in the literature to predict the creep data are those referred to materials where the substructure is supposed to change with stress $(n=5)(24,28-29)$ and those where the microstructure does not change with stress $(n=8)(23,32-33,46,50)$. An analysis of the present creep data was made by means of both mechanisms. The best fit was obtained by incorporating a threshold stress, $\sigma_{0}$, into the constant structure equation (eq. [2]). An agreement within an order of magnitude in strain rate between the experimental data and the prediction of eq. [2] was found for the extruded AFV-16\% material (51). Similar results were also found for a rolled AFV$27 \%$ material previously studied (46). However, the threshold stresses used were found to strongly depend on temperature. The variation of threshold stress in the range 573 to $823 \mathrm{~K}$ was 12 and 4 times for the rolled AFV-27\% and extruded AFV-16\% materials, respectively (46 and 51). This strong dependence on temperature of the threshold stress cannot be justified by microstructural changes and has not a physical meaning. Therefore, the threshold stress remains a fitting parameter. Considering the important structural applications of dispersion-strengthened alloys this is a serious practical limitation and its use should be avoided when extrapolating to lower stresses and/or higher temperatures.

As an interesting alternative to the use of a threshold stress, Arzt et al. developed a model where an attractive interaction of dislocations and precipitates is considered (42-43). The result of this attractive interaction is that dislocations remain attached to the dispersoids after local climbing until an equilibrium position, given by the strength of the interaction and the resolved shear stress, is reached. This mechanism is characterized by means of the parameters $k$, a relaxation parameter, which gives the strength of the attractive interaction, and $\tau_{\mathrm{d}}$, which gives the detachment shear stress necessary for dislocations to bypass the dispersoids without noticing the attractive interaction.

In order to compare the experimental data of the dispersion strengthened material with predictions from the Arzt model, values for $\mathrm{k}$ and $\tau_{\mathrm{d}}$ were obtained as a function of temperature to obtain the best correlation. Figure 3 shows the temperature dependence of $k$ for the extruded AFV-16\% material. It can be seen that $k$ is strongly temperature dependent. This temperature dependence of $k$ is not considered in the model. Similar dependence was obtained for $\tau_{\mathrm{d}}$. This may conclude that this model is not appropriate to predict the creep behavior of this material. In addition, a study conducted on the rolled AFV-27\% material (46) revealed that inconsistent sets of $k$ and $\tau_{d}$ values had to be used to predict either the apparent activation energy or the strain rate, but not both simultaneously. Moreover, the preexponential constant that had to be used to fit the creep data, was orders of magnitude higher than that predicted by the model.

Other authors approached the problem of the anomalous creep behavior by considering the deformation of dispersoids (36-37) or the load transfer between particles and matrix (38-39). However, the load transfer mechanism should be less important in this material than in whisker reinforced materials. On the other hand, TEM observations of deformed samples showed no deformation of the dispersoids (51). Moreover, in most dispersion strengthened materials the particles are impenetrable for dislocations and their concurrent deformation cannot occur. These results do not support the approach of Nix et al. (36-37) to describe the creep behavior of the Al-Fe-V-Si materials.

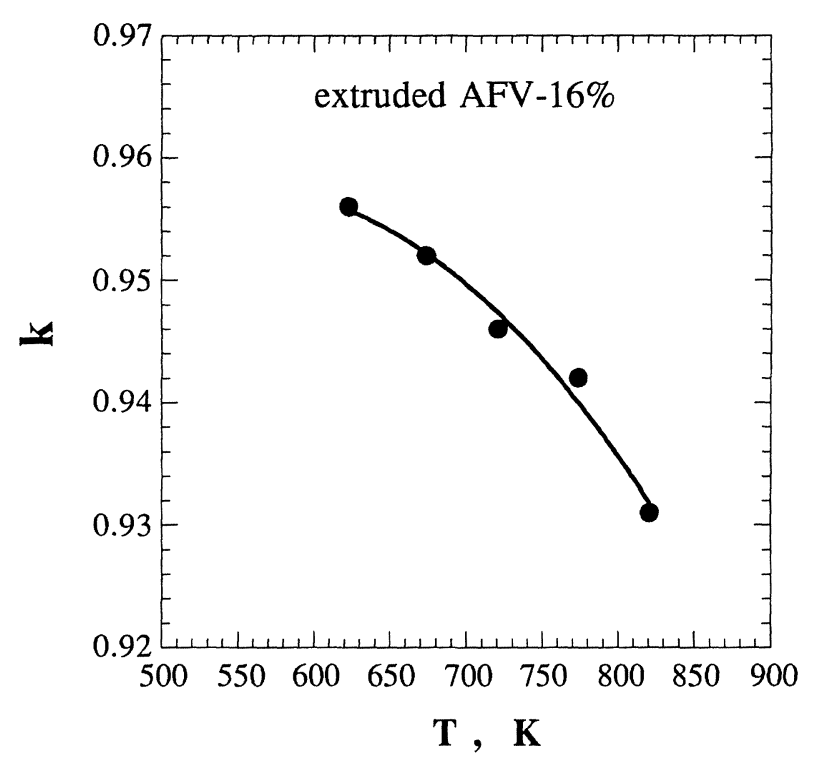

Fig. 3.-The relaxation parameter $v s$ testing temperature for the extruded AFV-16\% material.

Fig. 3.-El parámetro de relajación en función de la temperatura de ensayo del material AFV-16\% extruido. 
It is, therefore, concluded that the models given in the literature do not satisfactorily predict the creep data of the dispersion strengthened aluminum materials considered in this work. A new approach is developed in this work that is an alternative to existing models.

\subsection{Alternative creep equation for dispersion strengthened materials}

It is well established that the creep behavior of pure aluminum is characterized by a stress exponent of about 5 in the power law region. In addition, the activation energy for creep corresponds to that for lattice self-diffusion. Therefore, all creep data for pure aluminum at different temperatures can be superimposed into a single line in a representation of lattice diffusion compensated strain rate versus Young's modulus compensated stress in logarithmic scale. If the microstructure of the aluminum remains constant, a stress exponent of 8 would be found in this representation. As any creep data of pure aluminum lies along this single line, it is true that the creep data corresponding to a particular fixed strain rate for different temperatures lie also along the same line, thus showing the same stress exponent. Therefore, it would be sufficient to consider the creep data at a fixed strain rate to know the operating deformation mechanism for pure aluminum and other metals and alloys.

To better describe the creep behavior of dispersion strengthened materials, let us define the "skeleton line" as the line joining the creep data corresponding to the same reference strain rate (for example at $\left.10^{-4} \mathrm{~s}^{-1}\right)$ at different temperatures. Figure 4 shows the skeleton line of the extruded AFV-16\% material obtained at a constant strain rate of $10^{-4} \mathrm{~s}^{-1}$. In addition, a skeleton line of a previously tested $\mathrm{Al}-\mathrm{Fe}-\mathrm{V}-\mathrm{Si}$ material denominated "rolled AFV$27 \%$ " (46) is also incorporated into the figure. The choice of another strain rate does not alter the results. The lines in the figure are drawn from data at different testing temperatures.

Three distinct temperature ranges can be differentiated. At intermediate temperatures, power law breakdown occurs as shown by the curvature of the skeleton line at about $\dot{\varepsilon} / D_{\mathrm{L}}=10^{13} \mathrm{~m}^{-2}$. The power law region, i.e., the region at the highest temperatures, can be divided into two regions according to changes in the microstructure. Up to about $723 \mathrm{~K}$ the microstructure does not change during testing. At higher temperatures some microstructural coarsening takes place as a result of the higher diffusivity of the different elements present in the material. Only the creep data in the power law region will be considered in the following.

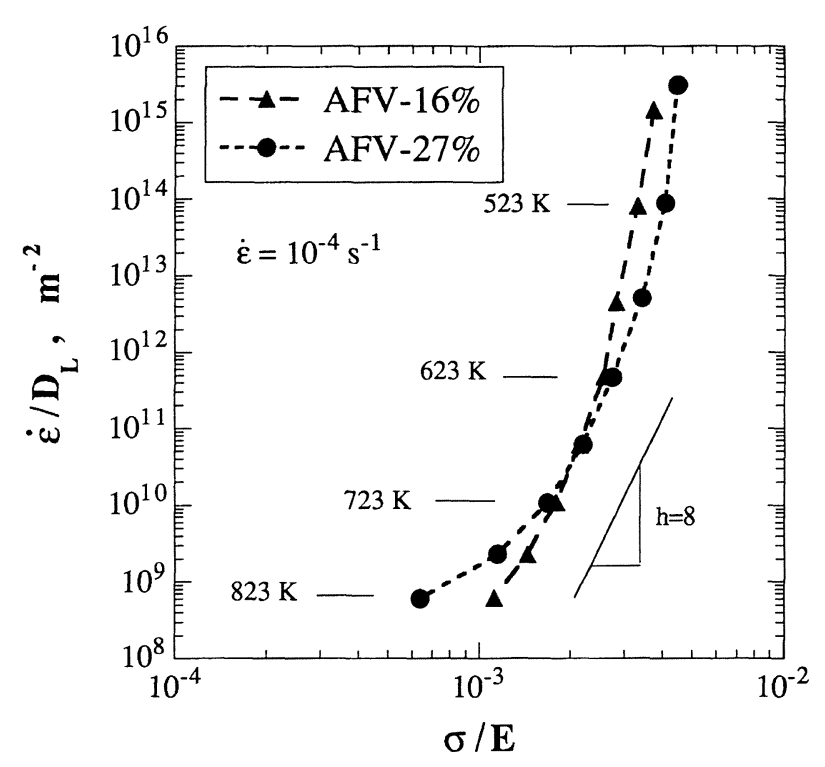

Fig 4.- - Lattice diffusion-compensated strain rate as a function of modulus-compensated stress for the extruded AFV-16\% and rolled AFV-27\% materials showing their "skeleton lines" at a constant strain rate of $10^{-4} \mathrm{~s}^{-1}$.

Fig 4._-Velocidad de deformación compensada por la difusión a través de la red en función de la tensión compensada por el módulo de Young de los materiales AFV-16\% extruido y AFV-27\% laminado mostrando sus "líneas de esqueleto" a una velocidad de deformación constante de $10^{-4} \mathrm{~s}^{-1}$.

The slope of the skeleton line is a stress exponent that will be named $h$. A value of $h=8$ is observed for the extruded AFV-16\% material in the power-law regime. This value of 8 agrees with the value of the stress exponent of the constant microstructure model, as given by eq. [2]. In contrast, the rolled AFV-27\% material shows a decreasing value from $h=8$ to about $h=5$, or lower, for increasing temperatures. This lowering of $h$ for the rolled AFV-27\% material is attributed to increasing microstructural coarsening and heterogeneization at increasing temperatures.

The value of $h$ is defined by the expression:

$$
h=\left.\frac{\partial \ln \left(\dot{\varepsilon} / D_{\mathrm{L}}\right)}{\partial \ln (\sigma / E)}\right|_{\dot{\varepsilon}}
$$

According to this definition, $h$ is a stress exponent that can be obtained from data at constant strain rate. The stress exponent, $h$, can be related to the apparent stress exponent, $n_{\mathrm{ap}}$, the apparent activation energy, $Q_{\mathrm{ap}}$, and the lattice diffusion activation energy, $Q_{\mathrm{L}}$, using the following relations for $n_{\mathrm{ap}}$ and $Q_{\mathrm{ap}}$, 


$$
n_{\text {ap }}=\left.\frac{\partial \ln \left(\dot{\varepsilon} / D_{\mathrm{L}}\right)}{\partial \ln (\sigma / E)}\right|_{\mathrm{T}} \quad Q_{\text {ap }}=n_{\text {ap }} \cdot R\left[\frac{\partial \ln (\sigma / E)}{\partial(1 / T)}\right]_{\dot{\varepsilon}}
$$

Applying the chain rule for partial derivatives, the following relation is derived:

$$
\begin{aligned}
& h=\left.\frac{\partial \ln \left(\dot{\varepsilon} / D_{\mathrm{L}}\right)}{\partial \ln (\sigma / E)}\right|_{\dot{\varepsilon}}=\frac{\partial \ln \left(\dot{\varepsilon} / D_{\mathrm{L}}\right)}{\partial(1 / T)}\left|\cdot \frac{\partial(1 / T)}{\partial \ln (\sigma / E)}\right|_{\dot{\varepsilon}}= \\
& =\frac{Q_{\mathrm{L}}}{R} \cdot \frac{n_{\text {ap }} \cdot R}{Q_{\text {ap }}}=Q_{\mathrm{L}} \cdot \frac{n_{\text {ap }}}{Q_{\text {ap }}} \text { or } \quad Q_{\text {ap }}=Q_{\mathrm{L}} \cdot \frac{n_{\text {ap }}}{h}
\end{aligned}
$$

Therefore, when $n_{\mathrm{ap}}=h$, then $Q_{\mathrm{ap}}=Q_{\mathrm{L}}$. In other words, if creep is exclusively controlled by lattice diffusion, $n_{\text {ap }}=h=n$ and the creep behavior is described by eq. [1] as for pure aluminum. It also follows from this equation that an increase of $n_{\text {ap }}$ is accompanied by an increase of $Q_{\mathrm{ap}}$, as it is observed for the studied dispersion strengthened materials.

It is our contention that the high values of $n_{\text {ap }}$ observed in dispersion-strengthened materials are attributed to an additional dependence of stress with strain rate from the presence of dispersoids. This is to be expected since the high $n_{\mathrm{ap}}$ and $Q_{\mathrm{ap}}$ values are observed in dispersion-strengthened materials and not in pure metals and alloys. According to this view, the interaction between dislocations and particles is a factor that influences slip creep. This can be considered as the core of the present approach. The magnitude of this interaction is described by a stress exponent, $\tilde{n}$, given by the relation:

$$
\tilde{n}=n_{\text {ap }}-h \quad \text { or, } \quad n_{\text {ap }}=h+\tilde{n}
$$

In other words, the dislocation-dispersoid interaction raises the stress exponent by a value of $\tilde{n}$. Therefore, $h$ is determined by the matrix behavior and $\tilde{n}$ by the dislocation-dispersoid interaction. The exponent $\tilde{n}$ can be, therefore, obtained for the extruded AFV-16\% material by substracting the slope of the skeleton line from the apparent stress exponent, both experimentally determined from figures 4 and 1 , respectively. The introduction of $\tilde{n}$ implies changes in the activation energy and in the pre-exponential constant of eq. [1]. Equation [7] together with eq. [6] predict that both the experimental apparent stress exponent and the activation energy are simultaneously increased for dispersion strengthened materials by means of $\tilde{n}$.

Similarly to the detachment model (42), it is our contention that the value of the parameter characterizing the dislocation-dispersoid interaction, $\tilde{n}$, is dependent on the particular dispersoid-matrix interface. Thus, vary for different materials.

The most general creep equation of our approach can be derived by introducing eqs. [6] and [7] into the general creep equation (eq. [1]):

$$
\dot{\varepsilon}=A \cdot\left(\frac{\sigma}{E}\right)^{\tilde{\mathrm{n}}+\mathrm{h}} \exp \left(\frac{-Q_{\mathrm{L}}}{R T} \cdot\left(\frac{\tilde{n}+h}{h}\right)\right)
$$

where $A$ is a material constant. Rearranging eq. [8], the different contributions of matrix and dispersoids can be separated:

$$
\dot{\varepsilon}=\left[A^{\prime}\left(\frac{\sigma}{E}\right)^{\mathrm{h}} \exp \left(\frac{-Q_{\mathrm{L}}}{R T}\right)\right]\left[B^{\prime}\left(\frac{\sigma}{E}\right)^{\tilde{\mathrm{n}}} \exp \left(\frac{-Q_{\mathrm{L}}}{R T} \frac{\tilde{n}}{h}\right)\right]
$$

It is readily apparent that the larger the interaction, i.e., the $\tilde{n}$ value, the more creep resistant is the material.

When the material deforms at high temperature maintaining its microstructure constant, a more explicit equation can be written:

$\dot{\varepsilon}=\left[A_{\lambda}\left(\frac{\lambda}{b}\right)^{3}\left(\frac{\sigma}{E}\right)^{8}\left(\frac{D_{\mathrm{L}}}{b^{2}}\right)\right]\left[B\left(\frac{\sigma}{E}\right)^{\tilde{n}} \exp \left(\frac{-Q_{\mathrm{L}}}{R T} \frac{\tilde{n}}{8}\right)\right][10]$

where $\lambda$ is the interparticle distance.

In summary, the apparent activation energy corresponds to that for self-diffusion of the matrix altered by the presence of dispersoids. The exponent $\tilde{n}$ causes an "amplification" of the strain rate dependence on temperature, predicting high apparent activation energy values. There is no need to invoke the operation of a threshold stress to rationalize the high apparent stress exponent and apparent activation energy values. Equation [8] presents also clearly the new approach by showing the two parameters, $h$ and $\tilde{n}$, describing the creep behavior of dispersion strengthened materials. These two parameters are related solely to the matrix behavior and the presence of dispersoids, respectively. Therefore, eq. [8] is a generalization of eq. [1] for dispersion-strengthened materials since for a non-reinforced material, $\tilde{n}=0$ and eq. [8] becomes eq. [1]. This equation describes the creep behavior of dispersion strengthened materials, not showing an apparent threshold stress, in a simple manner and is able to accurately predict the creep behavior, as long as there is no microstructural degradation and/or change in deformation mechanism, as will be shown in the following. 


\subsection{Predictive capability of the new equation}

Equation [8] was used to analyze and predict the creep behavior of the extruded AFV-16\% and rolled AFV-27\% materials. For the extruded AFV-16\% material a value of $h=8$ was used, as shown in figure 4, that is consistent with a constant microstructure slip creep mechanism, in contrast to a value of 5 implying stress dependent subgrain formation during creep. Values of $A=9.1 \cdot 10^{84} \mathrm{~s}^{-1}$ and $\tilde{n}=14$ were obtained by a minimum squares regression method to fit the experimental data. The value of $A$ is large because it is inversely proportional to the term $\sigma / E$ raised to the $n_{\text {ap }}$ exponent which is about 23.

Figure 5 shows the strain rate $v s$ the flow stress at five different temperatures for the extruded AFV$16 \%$ material. The predicted curves from eq. [8], using the previous values, correlate well with data at all temperatures except at the lowest temperature, $623 \mathrm{~K}$, where a lower creep rate is predicted. This can be associated with pipe and grain boundary diffusion that is believed to become important for fine grain size at intermediate temperatures. This can be taken into account by considering an effective diffusivity in eq. [8] instead of the lattice self-diffusivity used. The small disagreement at 821 $\mathrm{K}$ is attributed to microstructural changes involving coarsening of dispersoids. The relation between the

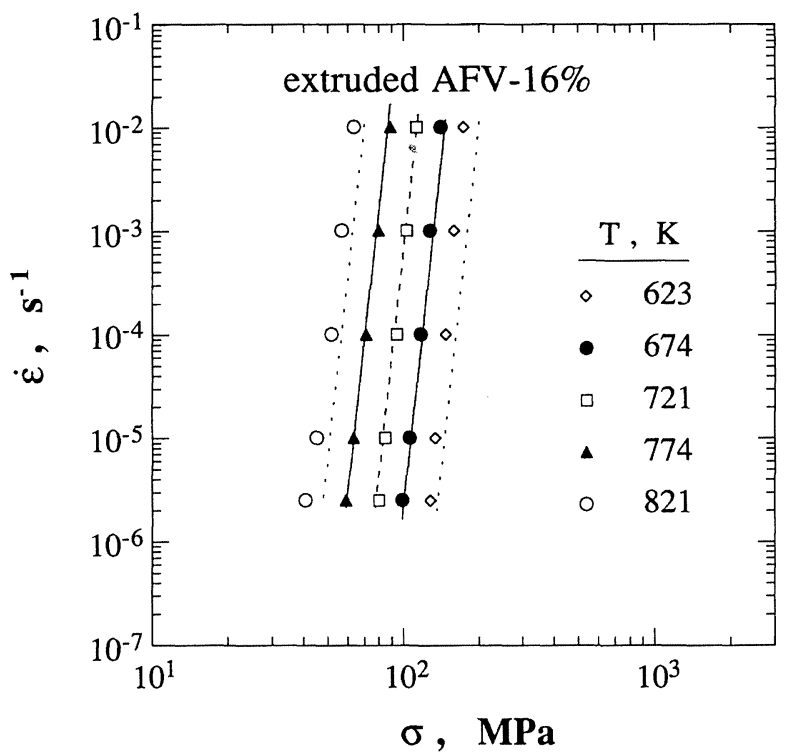

Fig 5.-The strain rate as a function of stress for the extruded AFV-16\% material at various temperatures. The lines are the predicted curves from eq. [8].

Fig 5.-La velocidad de deformación en función de la tensión a varias temperaturas del material $A F V$ $16 \%$ extruido. Las líneas están predichas mediante la ec. [8]. creep rate and the microstructural parameters will be considered later.

Figure 6 shows the strain rate as a function of the stress at five different temperatures for the rolled AFV-27\% alloy previously investigated (46). The following values of constants have been used: $h=8, \tilde{n}=12.5$ and $A=3.8 \cdot 10^{79} \mathrm{~s}^{-1}$. The figure shows experimental values of $\dot{\varepsilon}$ and $\sigma$ at different temperatures and the prediction of eq. [8] given as straight lines. The agreement between predicted values and experimental data is good except at 573 and $773 \mathrm{~K}$, due to the effective diffusivity and microstructural changes similar to those occurring in the extruded AFV-16\% material, respectively.

The small difference in $\tilde{n}$ values for the two materials $(\tilde{n}=12.5$ for the rolled AFV-27\% material and $\tilde{n}=14$ for the extruded AFV-16\% material) would indicate a slightly higher efficiency of the extruded AFV- $16 \%$ dispersoids to hinder the motion of dislocations. The preexponential constant $A$ is also 4 orders of magnitude larger for the extruded AFV-16\% material but it represents only about $30 \mathrm{MPa}$ in the stress axis, due to the large apparent stress exponent.

Another simple method to predict the creep behavior needs just three creep data: two at the same strain rate and at two different temperatures, and another one at a different strain rate for an

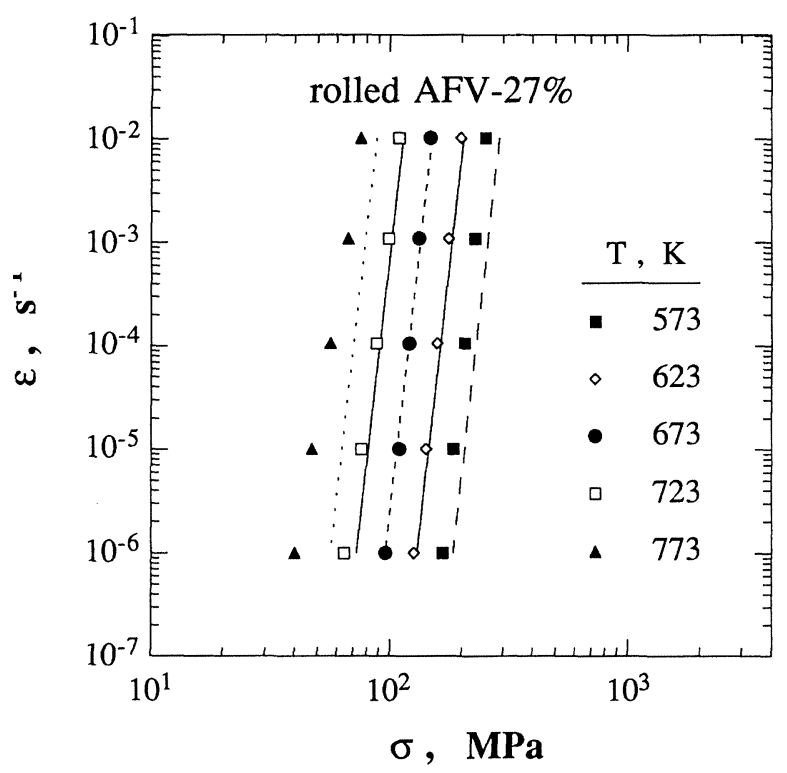

Fig 6.-The strain rate as a function of stress for the rolled AFV-27\% material at various temperatures. The lines are the predicted curves from eq. [8].

Fig 6.-La velocidad de deformación en función de la tensión a varias temperaturas del material AFV$27 \%$ laminado. Las líneas están predichas mediante la ec. [8]. 
already tested temperature. The values of $h$ and $n_{\text {ap }}$ are obtained from the two creep data at the same strain rate and from the two creep data at the same temperature, respectively. The value of $\tilde{n}$ can be calculated from these values by means of eq. [7], and $Q_{\mathrm{ap}}$ by means of eq. [6]. The constant $A$ can be calculated by introducing the $h$ and $\tilde{n}$ values into eq. [8], using a single experimental creep datum (one $\dot{\varepsilon}$ and $\sigma$ for a given $T$ ). As long as there is no change in microstructure and/or deformation mechanism, the given values of $Q_{\text {ap }}, n_{\text {ap }}$ and $A$ are constant and can be introduced into eq. [8] to predict the creep behavior.

Apart from explaining the high values of $Q_{\mathrm{ap}}$ and $n_{\text {ap }}$, our approach also explains the simultaneously strong temperature dependence of these parameters with temperature due to microstructural degradation involving coarsening and heterogeneization of the microstructure occurring at high temperatures. For constant $\tilde{n}$, according to eqs. [6] and [7], a decrease of $h$ causes a decrease of $n_{\mathrm{ap}}$ and an increase of $Q_{\mathrm{ap}}$.

The skeleton line, except for the preexponential constant, follows the constant microstructure equation (eq. [2]), as long as the interparticle distance is smaller than the equilibrium subgrain size for the flow stress, given by the relation (25 and 52):

$$
\frac{\lambda}{b}=A\left(\frac{\sigma}{E}\right)^{-1}
$$

where $A$ is approximately 7 for pure aluminum. Therefore, the change of $h$ can be quantified if microstructural changes are known. The value of $h$ can be related to the microstructure as follows:

$$
\begin{aligned}
& h=\left.\frac{\partial \ln \left(\dot{\varepsilon} / D_{\mathrm{L}}\right)}{\partial \ln (\sigma / E)}\right|_{\dot{\varepsilon}}=\frac{\partial \ln \left((\lambda / b)^{3}(\sigma / E)^{8}\right)}{\partial \ln (\sigma / E)}= \\
& =\frac{\partial \ln (\sigma / E)^{8}}{\partial \ln (\sigma / E)}+\frac{\partial \ln \lambda^{3}}{\partial \ln (\sigma / E)}=8+3 \frac{\partial \ln \lambda}{\partial \ln (\sigma / E)}
\end{aligned}
$$

If the microstructure remains constant, $\Delta \lambda=0$, and $h=8$. If the microstructure coarsens, $h<8$, since the derivative of $\lambda$ of eq. [12] is negative. This drop of $h$ induces a drop of $n_{\text {ap }}$ (eq. [7]) and an increase of $Q_{\mathrm{ap}}$ (eq. [6]).

An example of the effect of a microstructural change on $\mathrm{Q}_{a p}$ is given in the following for the rolled AFV-27\% material at $\dot{\varepsilon}=10^{-4} \mathrm{~s}^{-1}$ and at 673 and $723 \mathrm{~K}$. Stresses corresponding to a strain rate of $10^{-4} \mathrm{~s}^{-1}$ are considered although, as mentioned, any other strain rate can be considered. Assuming an increase of $\lambda$ of $25 \%$ the correction for $h$ from eq. [12], using the stress values from (46) is

$$
\Delta h=3 \frac{\ln (1.25)}{\ln \left(\frac{86 \cdot 55,187}{120 \cdot 52,271}\right)}=3(-0.8)=-2.4
$$

An experimental value of $h=7.4$ corresponded to the rolled AFV-27\% material at $673 \mathrm{~K}$. The prediction at $723 \mathrm{~K}$, as a result of microstructure coarsening, is therefore: $h=7.4-2.4=5$, that is the experimental value at $723 \mathrm{~K}$. The new $Q_{\text {ap }}$ value can be obtained through eq. [7], using $\tilde{n}=12.5$ for this material:

$Q_{\mathrm{ap}}=142(12.5+7.4) / 7.4=382 \mathrm{~kJ} / \mathrm{mol}$ at $673 \mathrm{~K}$ and

$Q_{\mathrm{ap}}=142(12.5+5.0) / 5.0=497 \mathrm{~kJ} / \mathrm{mol}$ at $723 \mathrm{~K}$.

These values agree closely with those experimentally determined (46).

Similar agreement can be obtained for the extruded AFV-16\% material. Assuming an increase of $\lambda$ of $15 \%$ from 721 to $774 \mathrm{~K}$, it is obtained $\Delta h \approx$ -1.9. Therefore, while at $721 \mathrm{~K}$ an apparent activation energy $Q_{\mathrm{ap}}=142(14+8) / 8=391$ $\mathrm{kJ} / \mathrm{mol}$ is predicted, a value of $Q_{\mathrm{ap}}=142(14+6.1) /$ $6.1=468 \mathrm{~kJ} / \mathrm{mol}$ is obtained at $774 \mathrm{~K}$ which is, again, close to the experimentally measured. Assuming again the same small increase of $\lambda$ of 15 $\%$ from 774 to $821 \mathrm{~K}$, it is obtained $\Delta h \approx-1.6$. A value for $Q_{\mathrm{ap}}=142(14+4.5) / 4.5=584 \mathrm{~kJ} / \mathrm{mol}$ is obtained at $821 \mathrm{~K}$ which is, again, close to the experimental value. This agreement gives an added support to the prediction capability of our approach.

It is worth noting that small changes in the microstructure, which are difficult to avoid in most families of dispersion strengthened alloys, cause strong changes in the creep behavior, i.e., in the creep resistance, $n_{\mathrm{ap}}$ and, specially, in $Q_{\mathrm{ap}}$.

In conclusion, the phenomenological model developed in this work describes well the creep behavior of the Al-Fe-V-Si materials. It can be also applied to the study of other dispersion strengthened materials.

\section{SUMMARY AND CONCLUSIONS}

- The microstructure of the extruded Al-Fe-V-Si material investigated was very fine. The dispersoids (about $54 \mathrm{~nm}$ ) pin the grain boundaries limiting the aluminum matrix grain size to a value of about $0.7 \mu \mathrm{m}$.

- High apparent stress exponents, ranging from 44 at $483 \mathrm{~K}$ to 19 at $821 \mathrm{~K}$, and high apparent activation energy values, up to $550 \mathrm{~kJ} / \mathrm{mol}$, were observed. These high $n_{\text {ap }}$ and $Q_{\text {ap }}$ values are in contrast to those of non-reinforced materials.

- The various models existent in the literature do not satisfactorily explain these high $n_{\mathrm{ap}}$ and $Q_{\mathrm{ap}}$ values. A new creep equation has been developed for dispersion-strengthened materials that do not show 
threshold stress-like behavior. This equation is a generalization of conventional slip creep equations and does not contain a threshold stress. The creep behavior of the matrix is characterized by $h$, the slope of the line that relates the lattice diffusion compensated strain rate and the modulus compensated stress at a constant strain rate. This line is called the skeleton line. An exponent $\tilde{n}$ is introduced that characterizes a dislocationdispersoid interaction which is temperature independent. The effect of the exponent $\tilde{n}$ is to increase the apparent stress exponent and the apparent activation energy respect to the values related to the matrix. The creep equation correctly predicts the creep behavior of aluminum dispersionstrengthened materials. It explains the high values of $Q_{\text {ap }}$ and $n_{\text {ap }}$, and, moreover, the simultaneous strong temperature dependence of these parameters that is due to microstructural degradation.

\section{Acknowledgments}

The authors gratefully acknowledge the support of the Comisión Interministerial de Ciencia y Tecnología (CICYT) under Grant No. MAT94/0888. Thanks are given to Dr. P.S. Gilman and Allied-Signal for providing the materials and for valuable information. Helpful discussions with Prof. O.D. Sherby are sincerely appreciated.

\section{REFERENCES}

(1) Pontikakos, I. and Jones H. Met. Sci., 16, 1982: 27.

(2) COUPER, M.J. and Singer, R.F. Processing of Structural Metals by Rapid Solidification. Ed. F.H. Froes and S.J. Savage. ASM, Metals Park, OH. 1986: 273.

(3) Rainen, R.A. and EkVAll, J.C. JOM, 5, 1988: 16.

(4) Fine, M.E. Dispersion Strengthened Aluminum Alloys. Ed. Y.W. Kim and W.M. Griffith, TMS, Warrendale, PA. 1988: 103.

(5) Champier, G., New Light Alloys, AGARD Lecture Series No. 174, Madrid (Spain), 1990: chapter 6E.

(6) Lavernia, E.J., Ayers, J.D. and Srivatsan, T.S. Int. Mater. Rev., 37, 1992: 1.

(7) Kawamura, Y., Inoue, A., Sasamori, K. and Masumoto, T., Scr. Metall. Mater., 29, 1993: 275.

(8) SkinNER, D.J. and OKAZAKI, K. Scr. Metall., 18, 1984: 905.

(9) Gogia, A.K., Rao, P.V. and Sekhar, J.A. J. Mater. Sci., 20, 1985: 3.091.

(10) KIRCHOFF, S.D. and KIM, Y.W. Processing of Structural Metals by Rapid Solidification. Ed. F.H. Froes and S.J. Savage, ASM, Metals Park, OH. 1986: 297.

(11) Kim, Y.W. and Froes, F.H. Processing of Structural Metals by Rapid Solidification. Ed. F.H. Froes and S.J. Savage, ASM, Metals Park, OH. 1986: 309.

(12) Gilman, P.S., Zedalis, M.S., Peltier, J.M. and Das, S.K. AIAA/AHS/ASEE Aircraft Design, Systems and Operations Conference. Ed. AIAA, Washington, D.C. 1988: 1.

(13) Skinner, D.J., Ramanan, V.R.V., Zedalis, M.S. and KIM, N.J. Mater. Sci. Eng., 99, 1988: 407.

(14) Chu, M.G. and Granger, D.A. Metall. Trans., 21A, 1990: 205.
(15) Gilman, P.S., Rateick, R.G. and Testa, A. Adv. Powder Metall. 6, 1991: 47.

(16) Cotton, J.D. and Kaufman, M.J. Metall. Trans., 22A, 1991: 927.

(17) Ramakrishnan, K.N., McShane, H.B., ShepPard, T. and IOANNIDIS, E.K. Mater. Sci. Techn., 8, 1992: 709.

(18) Ramakrishnan, K.N., McShane, H.B. and Sheppard, T. Mater. Sci. Techn., 9, 1993: 104.

(19) Skinner, D.J., Bye, R.L., Raybould, D. and Brown, A.M. Scr. Metall., 20, 1986: 867.

(20) Skinner, D.J., Bye, R.L., Raybould, D., Brown, A.M. and Zedalis, M. Processing of Structural Metals by Rapid Solidification. Ed. F.H. Froes and S.J. Savage, ASM, Metals Park, OH. 1986: 291.

(21) Lin, J. and SHerby, O.D. Res. Mech., 2, 1981: 251.

(22) Mohamed, F.A., Park, K.T. and Lavernia, E.J. Mater. Sci. Eng., A150, 1992: 21.

(23) GonzÁlez-Doncel, G. and Sherby, O.D. Acta Metall. Mater., 41, 1993: 2.797.

(24) Park, K-T., Lavernia, E.J. and Mohamed, F.A. Acta Metall. Mater., 42, 1994: 667.

(25) Sherby, O.D., Klundt, R.H. and Miller, A.K. Metall. Trans., 8A, 1977: 843.

(26) MurTY, G.S. and KocZAK, M.J. J. Mater. Sci., 24, 1989: 510.

(27) Tsuchiya, K., WeErtman, J.R. and Luton, M.J. Low Density, High Temperature Powder Metalurgy Alloys. Ed. W. E. Frazier, M.J. Koczak and P.W. Lee, The Minerals, Metals \& Materials Soc., 1991: 251.

(28) CAdeK, J. and SusteK, V. Scr. Metall. Mater., 30, 1994: 277.

(29) Cadek, J., Sustek, V. and Pahutova, M. Mater. Sci. Eng., A174, 1994: 141.

(30) Park, K.T., Lavernia, E.J. and Mohamed, F.A. Acta Metall. Mater., 38, 1990: 2.149.

(31) Park, K.T. and Mohamed, F.A. Scr. Metall. Mater., 30, 1994: 957.

(32) Mishra, R.S. and Pandey, A.B. Metall. Trans., 21A, 1990: 2.089.

(33) Pandey, A.B., Mishra, R.S. and Mahajan, Y.R. Acta Metall. Mater., 40, 1992: 2.045.

(34) Mishra, R.S. Scr. Metall. Mater., 26, 1992: 309.

(35) Mishra, R.S., Pandey, A.B., Prasad, K.S. and MukHERJeE, A.K. Scr. Metall. Mater., 33, 1995: 479.

(36) Oliver, W.C. and Nix, W.D. Acta Metall., 30, 1982: 1.335 .

(37) Yaney, D.L. and Nix, W.D. Metall. Trans., 18A, 1987: 893.

(38) Hong, S.H. and Chung, K.H. Key Eng. Mater., 104-107, 1995: 757.

(39) NARDONe, V.C. and Prewo, K.M. Scr. Metall., 20, 1986: 43.

(40) ARZT, E. and WiLkinson, D.S. Acta Metall., 34, 1986: 1.893.

(41) ARZT, E. and RÖSLER, J. Acta Metall., 36, 1988: 1.053.

(42) Rösler, J. and ARzT, E. Acta Metall., 38, 1990: 671.

(43) Rösler, J., Joos, R. and ARzT, E. Metall. Trans., 23A, 1992: 1.521.

(44) Mishra, R.S., Paradkar, A.G. and Rao, K.N., Acta Metall. Mater., 41, 1993: 2.243.

(45) Mishra, R.S., Nandy, T.K and Greenwood, G.W., Philos. Mag., A 69, 1994: 1.097.

(46) Carreño, F., González-Doncel, G. and Ruano, O.A., Mater. Sci. Eng., A164, 1993: 216.

(47) Das, S.K., Bye, R.L. and Gilman, P.S. Mater. Sci. Eng., A134, 1993: 1.103.

(48) Köster, W. Z. Metallkde., 39, 1948: 1.

(49) Sherby, O.D. and Burke, P.M. Progr. Mater. Sci., 13, 1967: 325 .

(50) Wolfenstine, J., González-Doncel, G. and Sherby, O.D. J. Mater. Sci. Lett., 9, 1990: 410.

(51) Carreño, F. Doctoral Thesis, Universidad del País Vasco, Leioa (Spain), 1994.

(52) RAJ, S.V. and Pharr, G.M. Mater. Sci. Eng., 81, 1986: 217. 